\title{
The Legal and Economic Aspects of Teaching High Technology Trends
}

\author{
Ekateryna. V. Astakhova ${ }^{1}$, Alexey Yu. Mamychev ${ }^{2}$, Sergey S. Shestopal ${ }^{3}$, Anna A. Kritskaya ${ }^{4} \&$ Ashkhen S. \\ Aroyan $^{5}$
}

${ }^{1} \mathrm{PhD}$ in Economics, Associate Professor of Economics and Management Department, Vladivostok State University of Economics and Service, Vladivostok, Russia. \& University of Economics and Service, Vladivostok, Russia

${ }^{2}$ Dr. habil. in political science, Phd in legal science, prof., Far Eastern Federal University

${ }^{3} \mathrm{PhD}$ in Law, Associate Professor of Law Department, Vladivostok State University of Economics and Service, Vladivostok, Russia

${ }^{4} \mathrm{PhD}$ in political science, Senior Lecturer of the South-Russian Institute of Management - Branch of the Russian Presidential Academy of National Economy and Public Administration

${ }^{5} \mathrm{PhD}$ in political science Associate Professor of the Department of Political Science and Ethnopolitics of the South-Russian Institute of Management - Branch of the Russian Presidential Academy of National Economy and Public Administration

Correspondence: Ekateryna. V. Astakhova, Associate Professor of Economics and Management Department, Vladivostok State University of Economics and Service, Vladivostok, Russia. \& University of Economics and Service, Vladivostok, Russia. E-mail: evastahova1@ya.ru/evastahova1@ya.ru

Received: July 17, 2019

doi:10.5430/ijhe.v8n7p132
Accepted: October 15, 2019

Online Published: October 28, 2019

\begin{abstract}
The main purpose of the article is to analyze The Legal and Economic Aspects of Teaching High Technology Trends. This is a descriptive-analytical study and the library method was used for data collection. Official statistics have also been used, reported by reputable sources and organizations of higher education. In the last stage it has approved that having academic education would facilitate the development in the industry as well as having promotion in academic background.
\end{abstract}

Keywords: high-tech production, legalization of high technology, industrial revolution, advanced technology products, economic growth, assessment, indicators of scientific and technical activity

\section{JEL Classification Code (up to 3-5)}

\section{Introduction}

We are on the verge of a technological revolution. A revolution that is fundamentally changing our lives, our work and our communications. This great transformation in scale and complexity is unlike any human experience. We do not yet know what the future of this great transformation will be. But one thing is clear: our response to this enormous transformation must be coherent and inclusive, covering all aspects of society, from the private and public sectors to civil society and academia (Avdeev \& Yurkovskaya, 2015; Bendikov, 2001; Braguinsky et al., 2011; Voychak, 2015; Glazev \& Haritonov, 2009; Jonathan et al., 2017; Simamora et al, 2019; Drexler, 2013; Kelley, 2006; Kizim, 2007; Marques et al, 2018).

There are reasons to suggest that today's developments are no longer the Third Industrial Revolution, but the promise of the emergence of the Fourth Industrial Revolution. The pace of new developments has no historical relevance. Compared to the Third Industrial Revolution, which has made linear progress, the Fourth Industrial Revolution is exponential. It also covers almost every industry. The breadth and depth of these changes promise to transform the whole production, management and control systems (Rigby, 2015; Kurfuss, 2014; Pussyrmanov et al, 2018; Orosz \& Ferenc, 2015).

The development of scientific knowledge began to call forth significant industrial transformations in the last decades of the XIX century, when the term "industrial revolution", which at the time meant the process of transition from agrarian economy to industrial society, passed into general usage. Currently, this term has a much wider interpretation (Smil, 2005; Securing the future of German manufacturing industry, 2018). Considering the concept of 
industrial revolutions, the following periodization can be offered. The first "Industrial" revolution (the end of the XVIII century - the second half of the XIX century) was triggered by the need for mechanization of the textile industry in the UK, the emergence of the steam engine, and the innovations in the production of cast iron. The second "Technological" revolution (the second half of the XIX century - the beginning of the XX century) was due to the innovative Bessemer steelmaking process, the emergence of flow-line production and assembly lines, based on scientific achievements rather than successful inventions, and closely related to the emergence of mass production and division of labor. The third "Information" revolution (the 1970s - the beginning of the XXI century) was caused by the use of computer equipment, $\mathrm{CNC}$ machines, the computer processing of high-quality and logistic information, the computerization of a wide range of manual tasks (accounting, inventory management, and planning). The fourth "Cognitive" revolution (the beginning of the XXI century) was called forth by a surge in scientific and technological development in various fields of knowledge, the use of cyber physical systems based on convergent NBIC-technologies (N (nano), C (cogno), B (bio), I (info)) for the introduction of the consumer-oriented "Internet of things", machine interaction technologies, the development of renewable energy sources, nanotechnologies, atomic precision manufacturing, etc (https:// www.unido.org; http://www3.weforum. Org; Global Manufacturing Outlook, 2016).

Right now, we live in the world of artificial intelligence: from driverless cars to drones, virtual assistants and translation software. In recent years, significant progress has been made in the area of artificial intelligence. These developments are due to the increased CPU power and availability of large amounts of information. Digital manufacturing technology is constantly interacting with the biological world.

Since 2001, after the publication of N. Roko (USA) (Roco, 2013), the concept of convergence of NBIC technologies as a basis for the Fourth industrial revolution appeared. This concept was actively used in the study of the impact of technological changes on the socio-economic development of society by scientists from the US, the EU, Japan, China, South Korea, and Brazil. This allows us to approach the creation of a new scientific and technical picture of the world and develop technologies not in one area, but in view of interdisciplinary connections (Securing the future of German manufacturing industry, 2018; The Third Revolution: The Convergence of the Life Sciences, 2011; https://www.globalinnovationindex.orglast, Matyushenko, 2017).

\section{Research Methods and Materials}

This is a descriptive-analytical study and the library method was used for data collection. Official statistics have also been used, reported by reputable sources and organizations. Finally, it should be added that the main approach in this study was comparative comparison.

\section{Results and Discussion}

Measuring progress is critical for policymakers and society. Countries that benefit from reliable statistics on their progress know where they stand, what their capabilities and limitations are, and most importantly, where they are going and how they want to get there. Among these are the indicators of the state of the art of advanced technology.

The main EU legal acts for cybersecurity are listed below. Most EU acts are directives and therefore require implementation in Member State national laws (and therefore entails a risk of diverting interpretations) (Glazev \& Haritonov, 2009; Ray, 2012). 
Table 1. The indicators of scientific and technical activity of the world's leading countries in 2016

\begin{tabular}{|c|c|c|c|c|c|c|c|c|c|}
\hline \multirow[b]{2}{*}{ Indicator sets } & \multicolumn{9}{|c|}{ Countries } \\
\hline & 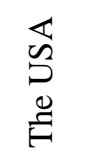 & 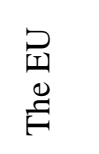 & 节 & 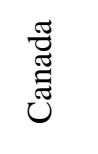 & 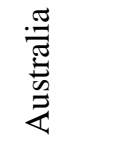 & 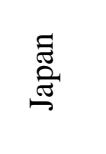 & 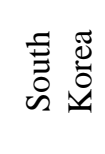 & $\begin{array}{l}\overline{\widetilde{N}} \\
\overline{\mathscr{n}}\end{array}$ & 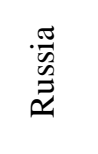 \\
\hline high-tech products [\% of GDP] & 77 & 65 & 70 & 63 & 64 & 72 & 69 & 57 & 42 \\
\hline Public spending [\% of GDP] & 0,72 & 0,72 & 0,46 & 0,80 & 0,86 & 0,75 & 0,87 & 0,63 & 0,48 \\
\hline Private spending [\% of GDP] & 1,94 & 1,22 & 1,58 & 1,76 & 1,19 & 2,79 & 3,36 & 0,52 & 0,71 \\
\hline $\begin{array}{c}\text { Applications [per } 1 \text { billion euros of } \\
\text { GDP] }\end{array}$ & 3,60 & 2,60 & 1,19 & 2,03 & 1,66 & 8,82 & 6,97 & 0,19 & 0,31 \\
\hline new doctorates per mille [ea] & 1,5 & 1,8 & 0,2 & 1,3 & 2,5 & 1,2 & 1,6 & 0,5 & 1,4 \\
\hline $\begin{array}{l}\text { population aged } 25-64 \text { with higher } \\
\text { education [\%] }\end{array}$ & 44,2 & 31,7 & 11,3 & 53,6 & 41,9 & 46,6 & 44,6 & 17,2 & 53,5 \\
\hline $\begin{array}{l}\text { coauthored international scientific } \\
\text { publications [ea] }\end{array}$ & 473,1 & 344,3 & 58,3 & 989,7 & 1413,5 & 186,7 & 331,4 & 72,0 & 85,8 \\
\hline national scientific publications [\%] & 14,0 & 10,5 & 8,2 & 11,8 & 12,2 & 6,5 & 6,2 & 4,9 & 3,3 \\
\hline Joint public-private publications [\%] & 62,1 & 33,9 & 4,6 & 32,0 & 23,6 & 44,6 & 58,4 & 1,8 & 1,7 \\
\hline $\begin{array}{l}\text { medium- and high-tech products goods } \\
{[\%]}\end{array}$ & 49,7 & 59,7 & 54,6 & 33,9 & 8,7 & 72,9 & 71,0 & 23,0 & 10,1 \\
\hline high-tech services in the total $[\%]$ & 46,7 & 56,1 & 39,9 & 46,4 & 35,6 & 32,0 & 45,1 & 64,7 & 42,1 \\
\hline foreign revenues from the sale [\%] & 0,748 & 0,585 & 0,009 & 0,223 & 0,061 & 0,800 & 0,365 & 0,016 & 0,036 \\
\hline
\end{tabular}




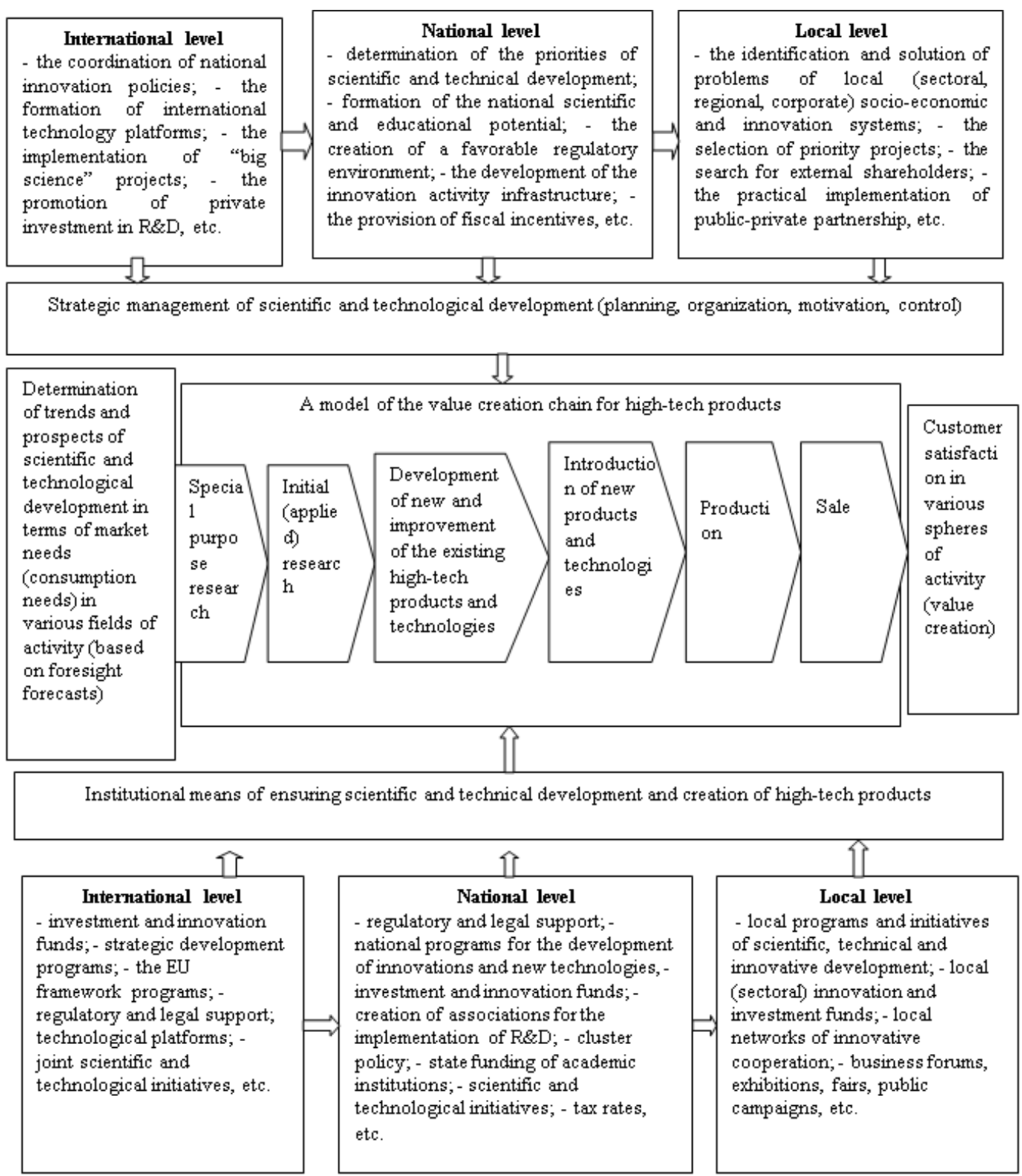

Figure 1. A model of the value creation chain for high-tech products

\section{Conclusions}

One of the fascinating and at the same time one of the most important issues facing the country is the discussion of the Fourth Industrial Revolution, a revolution based on digital technology that is far different in scale and complexity than humanity through the revolutions. Has previous industry experience. This revolution will bring about profound changes in other economic, social, and political sectors that will eventually be accompanied by some sort of civilization shift, as a result of drastic changes. The development of knowledge and the emergence of new technologies and technologies, at the same time as opportunities It poses countless threats to countries, and as the experience of the first to third industrial revolutions shows, the leadership and position of countries in the various areas of global segregation are influenced by the ability and capacity of countries to utilize this knowledge and technology. . Unfortunately, in the past industrial revolutions, our country failed to take advantage of the opportunities created by this revolution in its growth and development as well as in influencing the global economy and only becoming an end consumer of science and technology; With the advent of the Fourth Industrial Revolution it is being repeated again.

Science and technology indicators are useful in the implementation of future plans and policies of countries and will help to accurately identify the status quo. The first step in the process of evaluating the science and technology of 
each country is to define the indicators or the instruments for measuring the status quo. The indicators defined in countries should be consistent with those measured in most countries of the world to allow comparison with different countries. After defining a set of science and technology indicators, one must measure or calculate them. To this end, the existence of a single entity responsible for data collection should be considered.

To benefit from a sustainable economy, science and technology must move along, and the advent of advanced technology must take place with the advancement of science, since it is from the simplest to the most sophisticated industrial products based on the rapid advancement of science in various domains. Simply put, industrial production is a symbol of the progress of science and technology in countries. Thus, by comparing the production of industrial goods with state-of-the-art technology, one can infer the degree of development of science and technology in countries.

\section{Acknowledgement}

The study was carried out with the financial support of the Russian Foundation for Basic Research in the framework of research project No. 19-011-31031

\section{References}

Alexandria, (2012). Emerging Global Trends in Advanced Manufacturing. Wilson Center.

Avdeev, A. \& Yurkovskaya, G. (2015). The Development of High-Tech Production in Modern Russia. Scientific Journal on Philosophy, History, Historical Studies, Economy and Economics, Information Science, and Mathematics, 11, 120-134.

Bendikov, M. (2001). High-tech Product Markets: Trends and Prospects. Marketing v RossiiizaRubezhom: Scientific and Practical Journal, 2, 57-71(2001).

Braguinsky, S., Klepper, S. \& Ohyama, A. (2011). High-Tech entrepreneurship. Social Science Research Network, 3, 38-45(2011).

Drexler, E. (2013). Radical Abundance: How a Revolution in Nanotechnology Will Change Civilization. 1st edn. BBS PublicAffairs.New York.

Emerging trends in global manufacturing industries. UNIDO, Homepage, https:// www.unido.org/fileadmin/user_media/Services/PSD/Emerging_Trends_,last accessed 2018/08/15.

Eurostat Homepage, http://ec.europa.eu/eurostat/data/database, last accessed 2018/10/15.

Glazev, S. \& Haritonov, V. (2009). Nanotechnologies as a Key Factor of the New Technological Structure in the Economy. Trovant, Moscow.

Global Innovation Index Homepage, https://www.globalinnovationindex.orglast accessed 2018/04/15.

Global Manufacturing Outlook. (2016). Preparing for battle: Manufacturers get ready for transformation. KPMG. 34-42. Industry, Technology, and the Global MarketplaceHomepage, https://www.nsf.gov/statistics, last accessed 2018/04/15.

Jonathan, S., Kolodner, D. I. \& Mukhi, R. (2017). Cleary Discusses Cybersecurity and Data Privacy Developments: A Look Back on 2017 and Ahead to 2018. Columbia Law School's Blog on Corporations and the Capital Markets. http://clsbluesky.law.columbia.edu/2018/02/09/cleary-discusses-cybersecurity-and-data-privacy-developmentsa-look-back-on-2017-and-ahead-to-2018/

Kelley, T. (2006). The Ten Faces of Innovation. Strategies for Heightening Creativity. IDEO's Strategies for Beating the Devil's Profile Books Ltd., New York.

Kizim, N. (2007). High-Tech Industries as the Basis of the World's Competitiveness. Competitiveness: problems of science and practice-2007. Simon Kuznets Kharkiv National University of Economics Publishers, Kharkov.

Kurfuss, Th. (2014). Industry 4.0: Manufacturing in the United States. Bridges, 2.

Marques, B. P., Villate, J. E. \& Carvalho, C. V. (2018). Student Activity Analytics in an e-Learning Platfom: Anticipating Potential Failing Students. Journal of Information Systems Engineering \& Management, 3(2), 12.

Matyushenko, I. (2017). The Prospects for the Development of Convergent Technologies in the World and Ukraine for the Solution of Global Problems. Sole Proprietor,Kharkiv. 
Orosz, R. \& Ferenc, M. E. Z. O. (2015). Psychological Factors in the Development of Football-Talent from the Perspective of an Integrative Sport-Talent Model. Journal for the Education of Gifted Young Scientists, 3(1), 58-76.

Perez, C. (2009). Technological revolutions and techno 7 economic paradigms. Working Papers in Technology Governance and Economic Dynamics, 20, 23-29(2009).

Pussyrmanov, N., Rystina, I., Bulegenova, B., Askeyeva, G. \& Gabdulina, B. (2018). President Nursultan Nazarbayevs program article "The course towards future: Modernization of public consciousness"-ideology, value and political aspects. Opción, 34(85-2), 824-837.

Ray, O. (2012). High-Technology Entrepreneurship. Recherche, Paris.

Rigby, D. (2015). Technological Relatedness and Knowledge Space: Entry and Exit of US Cities from Patent Classes. Regional Studies, 49, 1922-1937(2015).

Roco, M. (2013). Convergence of Knowledge, Technology and Society: Beyond Convergence of NanoBio $\neg$ Info $\neg$ Cognitive Technologies. Springer, London (2013).

Securing the future of German manufacturing industry. (2018). Recommendations for implementing the strategic initiative. National Academy of Science and Engineering; German Research Center for Artificial Intelligence.Homepage. http://www.acatech.delast accessed 2018/04/15.

Simamora, R. E., Saragih, S. \& Hasratuddin (2019). Improving Students' Mathematical Problem Solving Ability and Self-Efficacy through Guided Discovery Learning in Local Culture Context. International Electronic Journal of Mathematics Education, 14(1), 61-72. https://doi.org/10.12973/iejme/3966

Smil, V. (2005). Creating the Twentieth Century: Technical Innovations of 1867-1914 and Their Lasting Impact. Oxford University Press; New York.

The Future of Manufacturing: Driving Capabilities, Enabling Investments. Global Agenda Council on the Future of Manufacturing; UNIDO, Homepage, http://www3.weforum. org/docs/Media,last accessed 2018/04/15.

The Third Revolution: The Convergence of the Life Sciences. (2011). Physical Sciences and Engineering. MIT, Washington.

Unctadstat. Homepage, http://unctadstat.unctad.org/wds, last accessed 2018/04/15.

Voychak, N. (2015). The Systematization of the Types of International Trade in High-Tech Products, 15-18, Tbilisi. 